\title{
PROTECCIÓN A LA VIVIENDA EN LAS SENTENCIAS DE LA CORTE INTERAMERICANA DE DERECHOS HUMANOS: ESCENARIOS Y CUMPLIMIENTO*
}

\author{
Magda Yadira Robles Garza* \\ Universidad Autónoma de Coahuila
}

\section{RESUMEN}

La protección a las personas o grupos sociales que no tienen una vivienda, o bien que, teniéndola, la han perdido por causa de guerras, desplazamientos internos o externos, violencia e inseguridad, requieren de una atención especial por parte de los Estados. Para atender este enfoque, a continuación se analizará el criterio o estándar establecido en el Sistema Interamericano de Derechos Humanos respecto a la protección de este derecho vía conexión de derechos. Las sentencias podrían exponer el estándar de protección que desde los gobiernos nacionales deben brindarse a las personas que pierden sus viviendas en estos contextos y, por otro lado, el papel del Estado en el cumplimiento de estas demandas, con la finalidad de conjeturar la declaración autónoma del derecho a la vivienda en la sede judicial de la región de las Américas.

Palabras Clave: vivienda, derechos humanos, justicia interamericana.

\section{PROTECTION OF HOUSING IN THE SENTENCES OF THE INTER-AMERICAN COURT OF HUMAN RIGHTS: SCENARIOS AND COMPLIANCE}

\section{Abstract}

Protection for people or social groups that do not have a home or who have it lost because of wars, internal or external displacement, violence and insecurity, require special attention from States. To address this approach, the criterion or standard established in the Inter-American System of Human Rights with respect to the protection of this right through the connection of rights will then be analyzed. The judgments could set out the standard of protection that from national governments must be afforded to people who lose their homes in these contexts and, on the other hand, the role of the State in complying with these claims, in order to conjecture the autonomous declaration of the right to housing in the judicial headquarters of the region of the Americas.

KEYwORDs: housing, human rights, inter-American justice. 


\section{SOBRE EL CONCEPTO DE VIVIENDA}

Los términos que comúnmente se emplean, tanto en la normatividad como en la vida cotidiana, para referirse al espacio natural o construido en el que habita temporal o permanentemente una persona o un grupo de personas ${ }^{1}$ pueden ser vivienda, vivienda digna, vivienda adecuada, o bien la vivienda razonable.

Según la perspectiva desde la que se analice el concepto serán los elementos que integren el mismo. Por ejemplo, el concepto urbano de vivienda refiere a metros cuadrados, número de habitaciones, desde esta visión subyace -sin dudala referencia a la ciudad. Desde una perspectiva ética, la vivienda referirá elementos de dignidad, a la «morada», «residencia». Desde otras miradas, la vivienda será el lugar donde confluyan los valores, costumbres, modos de ser de un grupo de personas, familias que crea bienestar para sus integrantes.

Una perspectiva diferente también puede distinguir entre el derecho al hogar del derecho a la vivienda. El primero tiene una mirada familiar y el segundo un enfoque patrimonial. También el derecho a la propiedad debe distinguirse de la vivienda, pues tener vivienda no es siempre un derecho de propiedad sobre la misma, o bien puede coincidir la propiedad en una vivienda, pero no necesariamente la segunda con la primera.

Otro debate del mismo modo interesante se presenta en la discusión respecto a que la vivienda forma parte de otro derecho más amplio como es «el derecho a un nivel de vida adecuado" como parece enunciar la Declaración Universal de los Derechos Humanos (en adelante, DUDH):

Artículo 25.

1. Toda persona tiene derecho a un nivel de vida adecuado que le asegure, así como a su familia, la salud y el bienestar, y en especial la alimentación, el vestido, la vivienda, la asistencia médica y los servicios sociales necesarios; tiene asimismo derecho a los seguros en caso de desempleo, enfermedad, invalidez, viudez, vejez u otros casos de pérdida de sus medios de subsistencia por circunstancias independientes de su voluntad.

2. La maternidad y la infancia tienen derecho a cuidados y asistencia especiales. Todos los niños, nacidos de matrimonio o fuera de matrimonio, tienen derecho a igual protección social.

* Este trabajo se ha realizado en el marco del proyecto de investigación Teorías de la justicia y derecho global de los derechos humanos (referencia PID2019-107172RB-I00), financiado por el Ministerio de Ciencia e Innovación de España.

** Doctora en Derechos Fundamentales por la Universidad Carlos III de Madrid. Profesora e investigadora del Centro de Estudios e Investigaciones Interdisciplinarios de la Universidad Autónoma de Coahuila. Actualmente, titular de la Defensoría de los Derechos Humanos Universitarios de la Universidad Autónoma de Coahuila, México. Investigadora Nacional SNI, nivel I.

1 Ferrando Salazar, E., «El derecho a una vivienda digna y adecuada», Anuario de Filosofía del Derecho, núm. IX, 1992, pp. 305-322, p. 306. 
O también en el derecho a la vida desde el punto de vista del derecho a contar con los elementos vitales para tener una existencia digna, entre ellos, la alimentación, salud, vestido, agua y vivienda ${ }^{2}$.

Igual como hace el Pacto Internacional de Derechos Económicos, Sociales y Culturales (en adelante, PIDESC) al reconocer en el artículo 11.1 «el derecho de toda persona a un nivel de vida adecuado" para sí y su familia, que incluye alimentación, vestido y vivienda adecuados, y una mejora continua de las condiciones de existencia. Los Estados Partes tomarán medidas apropiadas para asegurar la efectividad de este derecho, reconociendo a este efecto la importancia esencial de la cooperación internacional fundada en el libre consentimiento.

En definitiva, el concepto no es pacífico ni mucho menos concluyente. Al contrario, ocupa un lugar fundamental en el sistema jurídico de Naciones Unidas (en adelante ONU) a través de diferentes instituciones u órganos. Por mencionar algunos: Objetivos de Desarrollo Sostenible (ODS) número 11, respecto a lograr "ciudades y comunidades sostenibles»; ONU-Hábitat; la Relatoría Especial de ONU sobre el Derecho a la Vivienda Adecuada; el sistema de Informes Periódicos Universales, el Comité de Derechos Económicos, Sociales y Culturales de Naciones Unidas (en adelante, Comité DESC ONU), entre otras herramientas para el seguimiento y vigilancia de los compromisos de los Estados en esta temática en los niveles regionales y nacionales.

Sin embargo, a pesar de este lugar fundamental que ocupa el derecho a la vivienda tanto en el plano normativo como en el de las instituciones, se estima que millones de personas en el mundo viven en condiciones de peligro para su vida o su salud debido al hacinamiento, insalubridad y otras condiciones muy lejanas del respeto a los derechos humanos a una vida digna o un nivel de vida adecuado.

Así mismo, el mero hecho de contar con un lugar en el que residir no implica la satisfacción del derecho a la vivienda, pues, tal y como se precisa en el párrafo anterior, es necesario que se manifiesten condiciones que permitan la realización de otras necesidades como la alimentación, salud, educación, saneamiento, esparcimiento, entre otras ${ }^{3}$.

Por otro lado, el fenómeno de la migración abona la problemática de la vivienda desde la perspectiva de los desplazamientos forzosos que obligan a las personas a abandonar propiedades y formas de vida, precisamente, en un intento de poner a salvo esta.

La Relatoría Especial sobre la Vivienda Adecuada estima que 1600 millones de personas se alojan en viviendas inadecuadas y cerca de 900000 lo hacen en asentamientos informales, tanto en países de pocos recursos como en las naciones

2 Énfasis propio.

3 Sepulveda Mellado, O., «El espacio en la vivienda social y calidad de vida», Revista INVI, vol. 1, núm. 2, 1986, pp. 10-34, p. 306. 
con mayores ingresos. Esto sin contar las estadísticas sobre las personas sin techo, es decir, sin un lugar donde vivir ${ }^{4}$.

Ahora bien, tratando de reconstruir un concepto del derecho a la vivienda desde una perspectiva de derechos humanos, el primer paso sería acudir a la normatividad, es decir, el PIDESC, cuya referencia se encuentra dentro del concepto más amplio conocido como «derecho al nivel de vida adecuado».

Sin embargo, esta visión carece de contenido esencial o normativo acerca del derecho en sí mismo. Por lo que hay que buscar su configuración en otros lugares como lo dicho por la Relatoría de ONU en esta materia. Aquí explica que el derecho a tener vivienda no debe entenderse como limitada solamente a una vivienda básica. En lugar de ello, los Estados deben promover los entornos nacionales apropiados para hacer realidad este derecho (incluyendo hacer frente a las amenazas inmediatas a la vivienda), el desarrollo de políticas y prácticas para responder a las necesidades de vivienda a largo plazo por los cambios poblacionales, y la regulación de la provisión de vivienda por parte del sector privado, como lo ha sostenido la Relatoría al señalar que «los Estados deben reconocer y entender que la obligación de lograr el derecho a la vivienda recae en ellos y no puede ser delegada a los actores privados ${ }^{5}$.

La vivienda es una de las condiciones sociales básicas que determinan la igualdad y la calidad de vida de personas y ciudades. Factores como el lugar donde se ubican las viviendas, qué tan bien están diseñadas y construidas y qué tan bien se entrelazan con el tejido ambiental, social, cultural y económico influencian el diario vivir de las personas, su salud, su seguridad y su calidad de vida.

Como se aprecia, es un concepto multidimensional que requiere, adicionalmente, un análisis desde otros factores. Por mencionar alguno, el cambio climático, el desarrollo sostenible. En efecto, estos elementos afectan tanto a las generaciones actuales como a las futuras, dada la vida útil de las viviendas como estructuras físicas. Por todo esto, la vivienda es un elemento esencial para el desarrollo sostenible. Por una parte, la construcción y operación de viviendas consume una gran cantidad de recursos (suelo, energía, agua, materiales de construcción), al mismo tiempo que contamina el aire y el agua.

Por otra parte, las viviendas están expuestas a una variedad de impactos ambientales y riesgos tales como los desastres naturales y el cambio climático. Estos aspectos también adquieren una importancia considerable dentro del desarrollo sostenible. Esta compleja red de interrelaciones entre sostenibilidad y vivienda es uno de los temas principales de las políticas de viviendas sostenibles.

En suma, se trata de un concepto multivariable o que debe analizarse a partir de los elementos que lo integran. En este sentido, será importante, en principio, analizar el contenido esencial que el marco normativo ha dispuesto sobre este derecho.

${ }^{4}$ Noticias ONU, «Millones de personas viven sin techo o en casas inadecuadas, un asalto a la dignidad y la vida», 1 julio 2018. Disponible en https://news.un.org/ES/STORY/2018/07/1437721. 5 Idem. 


\subsection{Marco normativo aplicable}

La DUDH, en el ya citado artículo 25, establece el derecho a un nivel de vida adecuado, el cual comprende, entre otros, el derecho a la vivienda. Del mismo modo, el párrafo 1 del artículo 11 del PIDESC señala: «Los Estados partes reconocen el derecho de toda persona a un nivel de vida adecuado para sí y su familia, incluso alimentación, vestido y vivienda adecuados, y a una mejora continua de las condiciones de existencia».

El órgano encargado de interpretar y aplicar el PIDESC, es decir, el Comité DESC ONU, desde 1979 ha examinado informes relativos a la vivienda adecuada y examina documentación sobre la materia. A nivel normativo, de los instrumentos internacionales que abordan los diferentes aspectos del derecho a la vivienda, es el párrafo 1 del artículo 11 del PIDESC la más amplia y, sin duda, la más importante de todas las disposiciones en la materia.

También es relevante para nuestro estudio la Observación General N. ${ }^{\circ} 4^{6}$, particularmente porque establece los elementos esenciales que están en relación con este derecho. En primer lugar, la vivienda adecuada aplica a todos. Aunque sea común en los instrumentos internacionales y también en algunos textos constitucionales (como el caso mexicano), la referencia a "para sí y su familia», no se puede considerar hoy en día en el sentido de imponer una forma o estilo de vida determinado. Incluso el propio de concepto de «familia» debe ser entendido ampliamente y sin discriminación alguna.

Esto significa que tanto las personas (en su individualidad) como las familias tienen derecho a una vivienda adecuada, con independencia de la edad, situación económica, identidad sexual, afiliación a un determinado grupo, raza, etnia o de otra índole o factor. Por tanto, el derecho no está sujeto según el artículo 2 del PIDESC a ninguna forma de discriminación?

Segundo, el concepto de vivienda no es restrictivo a un lugar o cobijo. Sino un derecho a vivir en seguridad, paz y dignidad en algún sitio. Aquí la Observación General número 4 señala que este entendimiento se refiere a dos cuestiones inmersas en el concepto de vivienda: la dignidad inherente a toda persona y la vivienda debe ser adecuada.

En tal sentido, el término «adecuación» servirá para subrayar una serie de factores que hay que tener en cuenta al determinar si las viviendas pueden considerarse «adecuadas» para los efectos del PIDESC, considerando, por supuesto, los factores inherentes a cada comunidad o población como son los derechos sociales, económicos, culturales, ambientales, entre otros. Estos factores que subraya la Observación General número 4 se verán en detalle más adelante.

Otro instrumento normativo importante para la temática es la Observación General 7 emitida por el Comité DESC ONU, mediante la cual confirmó que los

${ }^{6}$ ONU, Comité DESC, Observación General núm. 4, 1991.

7 Comité DESC ONU, Observación General, Número 4, párr. 6. 
desalojos forzosos sólo pueden justificarse en las circunstancias más excepcionales y de conformidad con los principios pertinentes del derecho internacional, tales como los Principios Básicos y Directrices Sobre los Desalojos y el Desplazamiento Generados por el Desarrollo. Entre otras cosas, los Estados deben asegurar las garantías jurídicas, incluida la no discriminación, la no arbitrariedad, el debido proceso y la equidad procesal, junto con la consulta y la participación en la toma de decisiones, el acceso a los recursos, la compensación y el realojamiento adecuado ${ }^{8}$.

Un caso pertinente con esta temática tuvo que ver recientemente ${ }^{9}$, en virtud de la decisión emitida por el Comité DESC ONU en la que reconoce el derecho de los inquilinos a una vivienda adecuada cuando los residentes protestaron por los desalojos forzosos antes de un adecuado reasentamiento y rehabilitación. El Dictamen destaca la falta de ofrecimiento por parte del Estado de brindar a la familia una vivienda alternativa. Y, por otra parte, se señalan las obligaciones a cargo del Estado para proteger el derecho a una vivienda en los casos en que el desalojo esté justificado, es decir, por la falta del pago del alquiler, o bien por dańos a la propiedad. En estas situaciones, destaca el Comité DESC ONU que «es necesario que se cumplan ciertas condiciones: acceso a recursos efectivos, consulta con las personas afectadas, consideración de opciones alternativas, garantía de que ningún otro derecho será violado como consecuencia del desalojo, protección especial para los grupos vulnerables y suministro de vivienda alternativa $»^{10}$.

El Dictamen en este asunto es particularmente importante porque vuelve a afirmar la necesidad de aplicar un estándar de razonabilidad al acceder a las políticas de los Estados y para reconocer el derecho a una vivienda adecuada para todas las personas, incluyendo los inquilinos. También es útil para abordar una situación de violaciones sistémicas derivadas de medidas de austeridad adoptadas durante las crisis económicas.

En el ámbito universal debe destacarse la recepción del derecho a la vivienda adecuada en normas internacionales como la Convención Internacional sobre la Eliminación de Todas las Formas de Discriminación Racial ${ }^{11}$, la cual en el artículo 5 dice: «... los Estados partes se comprometen a prohibir y eliminar la discriminación racial en todas sus formas y a garantizar el derecho de toda persona a la igualdad ante la ley, sin distinción de raza, color y origen nacional o étnico, particularmente en el goce de los derechos siguientes:

... e)... (III) El derecho a la vivienda».

Por su parte, la Convención Internacional sobre la Eliminación de Todas las Formas de Discriminación contra la Mujer señala en el artículo 14.2.h que:

8 Villalibre Fernández, V., «El derecho a una vivienda adecuada. Un derecho del siglo XXI», Estudios de Progreso, Fundación Alternativas, núm. 64, 2011.

${ }^{9}$ Comité DESC ONU, 20 junio 2017.

${ }^{10}$ Comité DESC ONU, 20 junio 2017, párr. 15.2

${ }^{11}$ Adoptada el 21 de diciembre de 1965 y en vigor a partir del 4 de enero de 1969. 
Los Estados Partes adoptarán todas las medidas apropiadas para eliminar la discriminación de la mujer en las zonas rurales a fin de asegurar en condiciones de igualdad entre hombre y mujeres, su participación en el desarrollo rural y en sus beneficios, en en particular le asegurarán el derecho a: [...] (h) Gozar de condiciones de vida adecuados, particularmente en las esferas de vivienda, los servicios sanitarios, la electricidad y el abastecimiento de agua, el transporte y los comunicaciones.

El artículo 27 de la Convención de los Derechos del Niño expresa:

Los Estados Partes reconocen el derecho de todo niño a un nivel de vida adecuado para su desarrollo físico, mental, espiritual, moral y social. [...] 3. Los Estados partes, de acuerdo con las condiciones nacionales y con arreglos a sus medios, adoptarán medidas apropiadas para ayudar a los padres y a otras personas responsables por el niño a dar efectividad a este derecho, y en caso necesario proporcionarán asistencia material y programas de apoyo particularmente con respecto a la nutrición, el vestuario y la vivienda.

Así como la Convención sobre los Derechos de las Personas con Discapacidad establece en varios numerales el derecho de las personas con discapacidad a poder vivir en forma independiente y participar plenamente en todos los aspectos de la vida, los Estados deben adoptar medidas para asegurar su acceso al entorno físico. Estas medidas deben incluir la identificación y la eliminación de obstáculos y barreras de acceso; se aplicarán, por ejemplo, en los edificios, vías públicas, transporte, así como en escuelas, viviendas, instalaciones médicas y lugares de trabajo ${ }^{12}$. También la Convención les reconoce el derecho a un nivel de vida adecuado para ellas y sus familias, lo cual incluye alimentación, vestido y vivienda adecuada, así como el tener acceso a los programas de vivienda pública ${ }^{13}$.

Del mismo modo, otros instrumentos internacionales hacen referencia a la vivienda, como la Convención sobre el Estatuto de los Refugiados (1954), al establecer como derecho de los refugiados que se encuentren legalmente en sus territorios el trato más favorable posible en materia de vivienda (artículo 21).

Mientras que la Convención Internacional sobre la Protección de los Derechos de todos los Trabajadores Migratorios y de sus Familiares (2003) en el artículo 43.1 establace que los «trabajadores migratorios gozarán de igualdad de trato respecto de los nacionales del Estado de empleo en relación con d) acceso a la vivienda, con inclusión de los planes sociales de vivienda y la protección contra la explotación en materia de alquileres».

Hay otras disposiciones internacionales aplicables a derechos de los pueblos o comunidades indígenas que, como se verá más adelante, se encuentran estrechamente vinculadas con la tierra y el territorio como una forma de vida y, con ello, constituyen el lugar donde están sus asentamientos familiares, es decir, sus vivien-

12 Convención sobre los Derechos de las Personas con Discapacidad artículo 9.1. ${ }^{\mathrm{a}}$.

13 Convención sobre los Derechos de las Personas con Discapacidad, artículos 28.1 y 28.2.d. 
das. Especialmente relevante en esta materia es el Convenio 169 de la Organización Internacional del Trabajo (1991) en el artículo 20, referido a los derechos de los trabajadores pertenecientes a los pueblos indígenas; en particular, señala la obligación de los Estados de evitar la discriminación en el acceso a prestaciones sociales y del trabajo como la vivienda; o bien los artículos 21 y 23 de la Declaración sobre los Derechos de los Pueblos Indígenas (2007), que aluden a los derechos de los pueblos indígenas al mejoramiento de sus condiciones económicas y sociales en las esferas de educación, empleo y vivienda; así como a asegurar su participación en los programas relacionados con los temas de salud, vivienda y otros ${ }^{14}$.

En el ámbito interamericano son relevantes en primer lugar el artículo 26 de la Convención Americana sobre los Derechos Humanos, que refiere a la obligación de los Estados de adoptar las providencias necesarias para lograr progresivamente la plena efectividad de los derechos que se derivan de las normas económicas, sociales y sobre educación, ciencia y cultura contenidas en la Carta de la Organización de los Estados Americanos (en adelante, OEA).

En este sentido, el artículo 25 de la Convención Americana nos remite a la Carta de la OEA, así como al artículo XI de la Declaración Americana de los Derechos y Deberes del Hombre que expresa:

ARTículo 11. Derecho a la preservación de la salud y al bienestar.

Toda persona tiene derecho a que su salud sea preservada por medidas sanitarias y sociales, relativas a la alimentación, el vestido, la vivienda y la asistencia médica, correspondientes al nivel que permitan los recursos públicos y los de la comunidad.

Por otra parte, el texto de la Carta de la OEA, en su artículo 34 señala que:

Los Estados miembros convienen en que la igualdad de oportunidades, la eliminación de la pobreza crítica y la distribución equitativa de la riqueza y del ingreso, así como la plena participación de sus pueblos en las decisiones relativas a su propio desarrollo, son, entre otros, objetivos básicos del desarrollo integral. Para lograrlos, convienen asimismo en dedicar sus máximos esfuerzos a la consecución de las siguientes metas básicas:

k) Vivienda adecuada para todos los sectores de la población;

l) Condiciones urbanas que hagan posible una vida sana, productiva y digna ${ }^{15}$.

14 También pueden referenciarse otros instrumentos internacionales en temas de derecho internacional humanitario como los Convenios de Ginebra (1950) en los artículos 49, 85, 134, los cuales expresan los derechos de las personas que son trasladadas o evacuadas; la protección que se brinda a los bienes muebles e inmuebles para que no sean destruidos, con excepción de las destrucciones por operaciones bélicas; así como el deber de la potencia detenedora de tomar las medidas necesarias para que todas las personas sean alojadas desde el inicio del internamiento en edificios y con todas las garantías de higiene y salubridad que las protejan del clima y de la guerra.

${ }_{15}$ El énfasis es propio. 
También en el ámbito interamericano, la Convención Interamericana para la Eliminación de Todas las Formas de Discriminación contra las Personas con Discapacidad (2001) sostiene que los Estados se comprometen a adoptar las medidas necesarias para promover la prestación o suministro de bienes y servicios tales como empleo, transporte, vivienda, educación, deporte, entre otros (artículo III. 1. a). Así como otros dispositivos de la Declaración Americana sobre los Derechos de los Pueblos Indígenas (2016) en relación con la vivienda que protegen sus tierras o territorios ${ }^{16}$.

Es de notarse también la declaración expresa del derecho a la vivienda en la Convención Interamericana sobre la de los Derechos Humanos de las Personas Mayores (2015), cuyo numeral 24 señala: «Derecho a la vivienda», así como otros preceptos que indirectamente refieren a este derecho, como el artículo 12, que hace mención a los derechos de la persona mayor que recibe cuidados a largo plazo, que deberá contar, de acuerdo con este dispositivo, con un sistema integral de cuidados que le provea protección a la salud, cobertura de servicios sociales, alimentaria y nutricional, agua, vestuario y vivienda, entre otros.

El artículo 26 de dicho dispositivo señala sobre el derecho a la accesibilidad y movilidad que los Estados deben adoptar las medidas necesarias para asegurar el acceso de las personas adultas mayores a los servicios públicos y sociales como el transporte, entorno físico, las comunicaciones, así como la eliminación de barreras en las viviendas, edificios públicos, vías de comunicación, entre otros.

Para la construcción del concepto de «vivienda» al que hacen referencia estos instrumentos tanto internacionales como regionales ${ }^{17}$, los órganos e instancias de justicia del sistema universal y de los sistemas regionales han recurrido a los elementos o guías como las Observaciones Generales que se han elaborado a través del Comité DESC ONU. Estos elementos esenciales del concepto serán la guía clave para el entendimiento e interpretación de los casos que vivienda que veremos.

\subsection{Aspectos QUe INTEGRAN El CONCEPTO DE VIVIENDA ADECUADA}

Los factores que deben ser tenidos en cuenta como un mínimo deseable para la garantía del derecho a la vivienda adecuada son definidos y explicados por el Comité DESC ONU en los términos siguientes ${ }^{18}$ :

a) Seguridad jurídica de la tenencia. Se refiere al nivel de seguridad jurídica que las personas deben tener en relación con su situación de vivienda, con el fin de protección contra desalojos forzados, amenazas u hostigamiento. La protec-

16 Artículos VI, Xxv, Xxvi, XxIx, Xxx de la citada Declaración.

17 Véase Guiglia, G., «El derecho a la vivienda en la Carta Social Europea: a propósito de una reciente condena a Italia del Comité Europeo de Derechos Sociales», Revista de Derecho Político, núm. 82, 2011, pp. 543-578.

${ }^{18}$ Comité DESC ONU, OG. Número 4, párr. 8. 
ción a la vivienda puede adoptar diversas formas, tales como la propiedad legal, el alquiler o una cooperativa de vivienda.

b) Disponibilidad de servicios, materiales, instalaciones e infraestructura. Los Estados deben garantizar que las viviendas ofrecen las instalaciones necesarias para la salud, la seguridad, la comodidad y la nutrición. Esto incluye el acceso permanente a recursos naturales y comunes, el agua potable, la energía para cocinar, la calefacción e iluminación, las instalaciones sanitarias y de aseo, el almacenamiento de alimentos, la eliminación de desechos, el drenaje y los servicios de emergencia.

c) Gastos soportables. Se refiere a los gastos personales o del hogar, los cuales deberán ser de un nivel que no impida ni comprometa el logro y la satisfacción de las otras necesidades básicas, como alimentación y salud. El Estado debe adoptar las medidas necesarias para garantizar que el porcentaje de los gastos de vivienda sean coherentes con los niveles de ingreso. Por tanto, es necesario que los Estados creen subsidios, así como formas de financiación que correspondan con sus necesidades de vivienda.

d) Habitabilidad. La vivienda adecuada debe proporcionar a sus habitantes un espacio suficiente, ser segura para vivir y dar protección contra el frío, el calor, la lluvia y otros elementos de la naturaleza y riesgos estructurales. Los Estados deben prestar especial atención a la relación entre la vivienda inadecuada y las amenazas a la salud.

e) Asequibilidad. La vivienda y los costos relacionados con la vivienda deben ser proporcionales a los niveles de ingresos, y en un nivel que no comprometa otras necesidades básicas. Los Estados deberían crear subsidios de vivienda para los que no pueden costearse una, poner en marcha protecciones para los inquilinos frente a los alquileres no razonables y asegurar la disponibilidad de materiales naturales en las sociedades donde estos recursos sean las principales fuentes utilizadas para la construcción de viviendas.

f) Lugar. En muchos casos, tanto en las ciudades como en las zonas rurales, el transporte puede ser costoso y consumir mucho tiempo. La vivienda adecuada debe estar en un lugar que permita el acceso a las opciones de empleo, servicios de salud y educación y otros servicios sociales. Las casas no deben construirse en lugares peligrosos o contaminados.

g) Adecuación cultural. Los materiales de construcción de las viviendas deben estar conectados con la expresión de la identidad cultural y la diversidad de la vivienda, según corresponda a las comunidades dentro del contexto particular.

h) Accesibilidad. Todo el mundo debe tener acceso a una vivienda adecuada, especialmente los más vulnerables. Los Estados deben ofrecer vivienda prioritaria a los grupos más vulnerables. Los Estados deben elaborar planes de viviendas apropiadas para aumentar el acceso a la tierra de las personas sin hogar o los sectores empobrecidos de la sociedad.

Sin duda, uno de los elementos centrales que la Observación General N. ${ }^{\circ} 4$ señala es la debida prioridad a los grupos sociales que viven en condiciones desfavorables a través de una atención especial mediante políticas públicas o una estra- 
tegia general de vivienda que los Estados adopten, como se afirmó en la Estrategia Mundial de Vivienda. Este plan debe asegurar una consulta con las personas afectadas y su participación, incluidas las que no tienen hogar, las que han sido desalojadas y las que no tienen acceso a instalaciones básicas, o que viven en asentamientos ilegales, las que están sujetas a desahucios forzosos y los grupos de bajos ingresos ${ }^{19}$.

En este sentido, la protección a los grupos sociales que no tienen una vivienda, o bien que, teniéndola, la han perdido por causa de guerras, desplazamientos internos o externos, violencia e inseguridad, requieren de una atención especial por parte de los Estados. Para atender este enfoque, a continuación se analizará el criterio o estándar establecido en el Sistema Interamericano de Derechos Humanos respecto a la protección de este derecho en los países del continente.

\section{LA VIVIENDA EN EL SISTEMA INTERAMERICANO DE DERECHOS HUMANOS}

\subsection{Precisión respecto a la justiciabilidad de los DeSCA}

La protección a los DESCA y, en particular, el derecho a la vivienda en el sistema interamericano se establece a través de dos instrumentos normativos: la Convención Americana sobre Derechos Humanos $(\mathrm{CADH})$ a través del artículo 26 y el Protocolo Adicional a la CADH, conocido como Protocolo de San Salvador ${ }^{20}$, vía el artículo 11.

El texto del artículo 26 de la CADH señala lo siguiente:

Los Estados partes se comprometen a adoptar providencias, tanto a nivel interno como mediante la cooperación internacional, especialmente económica y técnica, para lograr progresivamente la plena efectividad de los derechos que se derivan de las normas económicas, sociales y sobre educación, ciencia y cultura, contenidas en la Carta de la Organización de los Estados Americanos, reformada por el Protocolo de Buenos Aires, en la medida de los recursos disponibles, por vía legislativa u otros medios apropiados (Convención ADH, 22 noviembre 1969).

Por su parte, el artículo 11 del Protocolo San Salvador hace una indirecta referencia a la vivienda al señalar el derecho a contar con servicios públicos básicos:

Artículo 11. Derecho a un medio ambiente sano.

1. Toda persona tiene derecho a vivir en un medio ambiente sano y a contar con. servicios públicos básicos ${ }^{21}$.

2. Los Estados Partes promoverán la protección, preservación y mejoramiento del medio ambiente.

19 Observación General Número 4, párrs. 12 y 13.

20 Protocolo adicional a la Convención Americana sobre Derechos Humanos en materia de Derechos Económicos, Sociales y Culturales (Protocolo de San Salvador).

${ }^{21}$ La cursiva es propia. 
En primer término, es relevante para nuestro estudio señalar que la situación normativa de este derecho determina la imposibilidad jurídica de su acción directa, pues la Corte IDH sólo tiene competencia para aplicar la propia Convención. Y extiende dicha competencia sólo por virtud del artículo 19.6 del Protocolo de San Salvador en lo que hace a los derechos de sindicación y a la educación. En tal sentido, aplicando la interpretación literal del texto del Protocolo, el derecho a la vivienda queda excluido de justiciabilidad directa ante los casos presentados a la Corte IDH.

En otros lugares me he referido ${ }^{22}$ a la jurisprudencia del tribunal interamericano, que elaboró, por vía de conexión e interdependencia de los derechos, una línea jurisprudencial para hacer justiciables algunos reclamos de índole económica, social o laboral, a través de su relación o conexión con el derecho a la vida o el derecho a la integridad personal ${ }^{23}$.

Por otro lado, es necesario señalar que a partir de 2017 la Corte IDH ha aplicado la norma 26 de la Convención directamente para proteger DESCA como derechos autónomos. Así lo estableció respecto al derecho al trabajo y a la estabilidad en el empleo ${ }^{24}$; el derecho a la salud tratándose de personas enfermas de VIH/SIDA ${ }^{25}$; o en el otro asunto referido al derecho a la salud pero de una persona adulta mayor ${ }^{26}$.

En 2019 dictó sentencia en la que determinó que la falta de materialización del derecho a la seguridad social por más de 27 años generó un grave perjuicio en la calidad de vida y la cobertura de salud del señor Muelle, una persona en situación de especial protección por ser persona mayor y en condición de discapacidad ${ }^{27}$. Más recientemente, la sentencia Miembros de la Asociación Lhaka Honhat (Nuestra Tierra) vs. Argentina ${ }^{28}$ declaró la vulneración a los derechos a la alimentación y al agua contra la comunidad indígena.

Sin embargo, el problema interpretativo es más complejo de acuerdo a la estructura normativa del precepto 26 de la $\mathrm{CADH}$. En otras palabras, no traslada el contenido ni la protección de los derechos a la Convención, ni al Protocolo de San Salvador, tampoco a la Declaración de los Derechos y Deberes del Hombre; lo hace a la Carta de la Organización de los Estados Americanos (OEA) y este enfoque competencial, es precisamente uno de los principales argumentos esgrimidos por

22 Robles Garza, M., «El derecho a la salud en la Corte Interamericana de Derechos Humanos (2004-2014)», en Cuestiones Constitucionales, número 35, julio-diciembre 2016, pp. 199246. ISSN para la versión electrónica: 2448-4881. Disponible en http://revistas.juridicas.unam.mx/ index.php/cuestiones-constitucionales/article/view/10496/12662.

${ }^{23}$ Artículos 4 y 5 de la CADH.

${ }^{24}$ Corte IDH, Lagos del Campo vs. Perú, 31 agosto 2017 y Corte IDH, Trabajadores Cesados de Petroperú y otros vs. Perú, 23 noviembre 2017.

25 Corte IDH, Cuscul Pivaral y otros vs. Guatemala, 23 agosto 2018.

${ }^{26}$ Corte IDH, Poblete Vilches y otros vs. Chile, 8 marzo 2018.

27 Corte IDH, Muelle Flores vs. Perú, 6 marzo 2019.

${ }^{28}$ Corte IDH, 6 febrero 2020. 
los jueces discordantes en las sentencias que declararon la vulneración del DESCA de manera autónoma.

Otro dato interesante a comentar. Este debate interpretativo ha sido producto de dos fuerzas impulsoras: por instancia de la Comisión IDH o los representantes de las víctimas, o bien por iniciativa de los propios jueces interamericanos. Hemos sido testigos de una ardua disputa en los últimos diez años respecto a la toma de postura sobre la justiciabilidad directa o indirecta de estos derechos.

Sin embargo, como he apuntado antes, en el tema de vivienda el derecho no ha sido declarado autónomo ni tampoco protegido directamente. Lo que sí ha hecho la Corte IDH hasta ahora ha sido proteger la vivienda de las víctimas y sus familiares mediante la vía de conexión gracias al argumento de la interdependencia de los derechos y la conexión entre los mismos.

Por tanto, interesa aquí mostrar una sistematización de 21 decisiones judiciales interamericanas que permita visibilizar este trabajo interpretativo respecto a la garantía y protección de la vivienda. Para ello, se analizará en el siguiente apartado a través de una doble visión la protección a la vivienda: por un lado, de manera indirecta o por vía de conexidad a través de la aplicación de la CADH, y, por el otro, a través de las medidas de reparación integral impuestas a los Estados en dichas sentencias.

Para sistematizar las sentencias se siguió esta metodología: primero, se realizó una búsqueda de las sentencias de Fondo emitidas por la Corte IDH desde su primera sentencia en 1987 hasta fecha de corte de este documento: 20 de julio de 2020. En total, se encontraron 21 sentencias cuyas temáticas centrales hacen referencia a la pérdida de la vivienda de las víctimas y/o sus familiares a través de otros derechos convencionales. Se dividieron según sea el derecho que se consideró vulnerado por la Corte IDH como el derecho a la propiedad; el derecho a la circulación o al movimiento; la libertad personal, todos de la CADH.

Segundo, en cada uno de estos rubros se analizan -a la par del tema de fondo- las 28 medidas de reparación integral impuestas a los Estados en materia habitacional. Tercero, se hace referencia de manera breve al cumplimiento de los Estados de tales medidas. Y, finalmente, en las reflexiones finales se comentan algunas voces judiciales que exponen una vía de justiciabilidad directa del derecho a la vivienda a través del artículo 26 de la Convención Americana.

\subsection{LOS ESCENARIOS DE PROTECCIÓN DE LA VIVIENDA}

\subsubsection{El derecho a la propiedad privada (artículo 21 de la CADH)}

Para nuestro análisis es relevante destacar cómo estas sentencias muestran los escenarios en los cuales el derecho a la vivienda es protegido a través de su relación o conexión con otros derechos: el derecho a la propiedad, el derecho a la circulación o residencia para los casos de desplazamiento y también el derecho a la vida privada libre de injerencias en asuntos de desaparición de personas, ejecuciones y actos de tortura o privación ilegal de la libertad, entre otros.

Para iniciar con el primer escenario, la propiedad, cabe señalar que la Corte IDH desarrolló el concepto «amplio» de propiedad dándole un giro interpretativo 
por el cual integró una valoración "comunal» o «colectiva» en ciertos asuntos referidos principalmente a los territorios de los pueblos y comunidades indígenas ${ }^{29}$.

Por tanto, aquí se presentan los asuntos en aquellos que hacen referencia al tradicional concepto de propiedad privada y su conexión con la vivienda; posteriormente, a los referidos a las comunidades y pueblos indígenas en los que el concepto de colectividad se relaciona con los lugares donde residen estas comunidades.

Respecto al primero, la propiedad privada comprende el uso y goce de bienes. La definición empleada por el Tribunal para los bienes incluye "cosas materiales apropiables, tanto muebles como inmuebles, elementos corporales o incorporales así como cualquier otro objeto inmaterial susceptible de valor, en suma, todo aquello que pueda formar parte del patrimonio de una persona $»^{30}$.

En este mismo sentido, el Alto Tribunal ha sostenido que los derechos a la vivienda y a la propiedad están vinculados como derechos humanos interdependientes, también afirma que «toda vivienda puede ser protegida mediante el derecho a la propiedad, pero no toda propiedad es necesariamente vivienda ${ }^{31}$.

En este asunto, la Corte sostuvo -apoyándose en el Comité DESC ONUque, aunque el derecho a la vivienda es el derecho de toda persona a un lugar seguro, asequible y habitable, esta concepción no comprende toda propiedad ${ }^{32}$.

Para facilitar la exposición de estos criterios de propiedad privada he optado por agrupar los casos según las temáticas que abordan los asuntos: a) desplazamientos forzados, b) desapariciones forzadas, masacres y ejecuciones arbitrarias y, finalmente, c) las comunidades indígenas.

La primera de estas temáticas son los asuntos en los que las víctimas han tenido que desplazarse del lugar donde habitan debido a la destrucción o afectaciones estructurales a la vivienda, que suponen un costo económico, además de las condiciones de movilidad o desplazamiento. En asuntos como Yarce y otras, el Tribunal se pronuncia a favor de proteger la propiedad de la víctima, así como de reparar los daños morales y económicos que sufrió su familia por motivo del desplazamiento interno que tuvieron que realizar por peligro a sus vidas ${ }^{33}$.

El desplazamiento forzado es el escenario en la jurisprudencia interamericana que señala la necesidad de proteger el derecho a la vivienda. En efecto, es posible encontrar en aquellos asuntos que plantean el apremio de las víctimas para salvaguardar su vida y la de sus familiares el tener que abandonar su lugar de residencia, su domicilio, ya sea por la destrucción de sus viviendas, por conflictos internos, por el ejercicio de su profesión, entre otras causas más.

${ }^{29}$ Corte IDH, Comunidad Mayagna (Sumo) Awas Tingni vs. Nicaragua, 31 agosto 2001, párrs. 149-152.

${ }^{30}$ Corte IDH, Salvador Chiriboga vs. Ecuador, 6 mayo 2008, párr. 55; Corte IDH, Ivcher Bronstein vs. Perú, 6 febrero 2001, párrs. 120-122.

${ }^{31}$ Corte IDH, Vereda La Esperanza vs. Colombia, 31 agosto 2017, párr. 240.

32 Comité DESC ONU, Observación General Número 4, 1991, párr. 8

33 Corte IDH, Yarce y otras vs. Colombia, 22 noviembre 2016, párrs. 55-64. 
El artículo 22 de la CADH establece que el derecho a la circulación y a la residencia es:

1. Toda persona que se halle legalmente en el territorio de un Estado tiene derecho a circular por el mismo y, a residir en él con sujeción a las disposiciones legales.

2. Toda persona tiene derecho a salir libremente de cualquier país, inclusive del propio.

3. El ejercicio de los derechos anteriores no puede ser restringido sino en virtud de una ley, en la medida indispensable en una sociedad democrática, para prevenir infracciones penales o para proteger la seguridad nacional, la seguridad o el orden públicos, la moral o la salud públicas o los derechos y libertades de los demás.

4. El ejercicio de los derechos reconocidos en el inciso 1 puede asimismo ser restringido por la ley, en zonas determinadas, por razones de interés público.

5. Nadie puede ser expulsado del territorio del Estado del cual es nacional, ni ser privado del derecho a ingresar en el mismo.

6. El extranjero que se halle legalmente en el territorio de un Estado parte en la presente Convención, sólo podrá ser expulsado de él en cumplimiento de una decisión adoptada conforme a la ley.

7. Toda persona tiene el derecho de buscar y recibir asilo en territorio extranjero en caso de persecución por delitos políticos o comunes conexos con los políticos y de acuerdo con la legislación de cada Estado y los convenios internacionales.

8. En ningún caso el extranjero puede ser expulsado o devuelto a otro país, sea o no de origen, donde su derecho a la vida o a la libertad personal está en riesgo de violación a causa de raza, nacionalidad, religión, condición social o de sus opiniones políticas.

9. Es prohibida la expulsión colectiva de extranjeros.

En este sentido, en el artículo 22 de la $\mathrm{CADH}$ debe entenderse que el desplazamiento forzado tanto interno como externo, incluso «interurbano», puede llegar a configurarse en situaciones en las cuales dicho desplazamiento es propiciado por conflictos armados, violencia generalizada o violaciones de derechos humanos.

En cualquier caso, se trata de una situación donde, además de vulnerar el derecho a la circulación o la residencia, se asocia con la afectación a otros derechos humanos como la vida, la salud, el trabajo y, por supuesto, con las condiciones de una vivienda digna, así como otros bienes como menaje de la casa, dinero, medicamentos, joyas, artículos personales como ropa, hasta ganado o cultivos ${ }^{34}$.

Por ejemplo, uno de los casos paradigmáticos en los que la Corte IDH ha aplicado este criterio es Masacres de El Mozote y lugares aledaños vs. El Salvador ${ }^{35}$. En él la Corte IDH sostuvo que los militares despojaron a las víctimas de sus pertenencias, quemaron sus viviendas y cultivos y mataron al ganado; estas acciones de miembros de la Fuerza Armada afectaron varios derechos, entre los cuales se encuentra la

${ }^{34}$ Corte IDH, Familia Barrios vs. Venezuela, 24 noviembre 2011, párrs. 148-150; Uzcátegui y otros vs. Venezuela, 3 septiembre 2012, párr. 203.

${ }_{35}$ Corte IDH, 25 octubre 2012. 
pérdida definitiva de las propiedades de sus víctimas y la destrucción de sus hogares $^{36}$. Esto llevó al Tribunal a señalar que la vulneración del artículo 22, es decir, el ser obligados a desplazarse de sus viviendas, no sólo implicó el menoscabo de los bienes materiales, sino la pérdida de las más básicas condiciones de existencia y de desmembramiento del tejido social de estos poblados ${ }^{37}$.

Para nuestro análisis es relevante destacar cómo estas sentencias muestran otro escenario donde el derecho a la vivienda es protegido a través de su relación o conexión con otros derechos, como el derecho a la vida privada libre de injerencias. Esto es, a través de estas acciones -la masacre de estos poblados- los sobrevivientes fueron forzados a salir de sus viviendas dejando a campesinos y amas de casa sin un lugar donde habitar y sin medios para subsistir ${ }^{38}$; y por otro lado, el Estado tampoco favoreció el retorno seguro y digno de la población civil sobreviviente a sus lugares de residencia durante muchos años, ni tampoco cercioró el reasentamiento voluntario en otra parte del país, como lo describe la propia sentencia ${ }^{39}$.

En lo que respecta a las medidas de reparación integral que contempla la sentencia de El Mozote, la Corte IDH ordenó a El Salvador garantizar a las víctimas desplazadas las condiciones adecuadas para el retorno a sus comunidades de origen de manera permanente e implementar un programa habitacional en las zonas afectadas por las masacres ${ }^{40}$.

En otro asunto, Vereda la Esperanza vs. Colombia ${ }^{41}$, la Corte IDH, empleando el principio iura novit curia ${ }^{42}$, desprendió tres hechos relacionados con la vivienda: por

36 Corte IDH, Masacres de El Mozote y lugares aledaños vs. El Salvador, 25 octubre 2012, párrs. 168 y 175.

${ }^{37}$ Corte IDH, Masacres de El Mozote y lugares aledaños vs. El Salvador, párr. 208. En la sentencia la perito Yáñez De La Cruz, describió: «[n]o s[ó]lo se acabó con la población civil, sino con todo el entramado social y simbólico. Destruyeron casas, y objetos significativos[.] Les despojaron de sus prendas de vestir, de los juguetes de los nińos, de sus fotos familiares, quitaron y arrasaron con todo lo significativo para ellos. Mataron y desaparecieron animales, todos relatan [s]e llevaron las vacas, las gallinas, se llevaron mis vacas, mataron a dos toros: una p[é]rdida de significación tanto afectiva como material, en el universo campesino. Tierra arrasada constituye una marca de vulneración y estigmatización de los militares que los victimarios crearon. La dimensión del horror perpetrado allá quiso acabar con la zona, con toda su gente, vaciar el territorio, expulsarles de allá». "[f]ue una lógica de exterminio, una destrucción total de los espacios sociales. [...] La masacre disolvió la identidad colectiva, al dejar un vacío social, donde la comunidad hacia sus ritos, sus intercambios afectivos, el contexto y el marco en el que se sabían parte de la comunidad» (Corte IDH, Masacres de El Mozote y lugares aledaños vs. El Salvador, párr. 180).

${ }^{38}$ Corte IDH, Masacres de El Mozote y lugares aledaños vs. El Salvador, párr. 183.

39 Corte IDH, Masacres de El Mozote y lugares aledaños vs. El Salvador, párrs. 192-193.

${ }^{40}$ Corte IDH, Masacres de El Mozote y lugares aledaños vs. El Salvador, párrs. 345 y 346.

${ }^{41}$ Corte IDH, 31 agosto 2017.

${ }^{42}$ Se intrerpreta que el juzgador posee la facultad e incluso el deber de aplicar las disposiciones jurídicas que estime convenientes al asunto, por su posición de «conocedor» del Derecho cuando las partes no lo hayan invocado de manera explícita (Corte IDH, Velasquez Rodríguez vs. Honduras, 21 julio 1989, párr. 163), entre otros asuntos. 
un lado, el allanamiento de la misma; la destrucción de las cosas muebles que estaban dentro la casa; y, finalmente, los dańos provocados a la estructura de la vivienda ${ }^{43}$.

Estas circunstancias provocaron que las familias abandonaran la vivienda trasladándose a vivir con otros miembros de la familia. En este sentido, la Corte reflexiona sobre dos aspectos claves: por un lado, los dańos estructurales causados a las viviendas, es decir, protegió estos hechos a partir del artículo 21 de la Convención diciendo que las viviendas entraban en la categoría protegida por el derecho de propiedad de bienes inmuebles. Y, por otro, el costo económico que supone su reparación o pérdida de las viviendas que no pudieron ser habitadas, así como la otra pérdida: la de las condiciones básicas de existencia digna.

En este asunto, la Corte IDH declara la vulneración de los dos derechos aquí analizados en contexto con la pérdida de las viviendas de la comunidad; sin embargo, no existen medidas de reparación específicas sobre vivienda. Lo que sí dice la sentencia es la condena al Estado de efectuar el pago de la indemnización correspondiente por daños a la propiedad privada ${ }^{44}$.

Similar respuesta da la Corte en la sentencia dictada en el asunto Masacre de Santo Domingo, pues sostuvo que la situación de desplazamiento forzado interno que enfrentaron las víctimas que resultaron heridas y sus familiares fue consecuencia de la explosión del dispositivo cluster en el caserío de Santo Domingo, además de las afectaciones psicológicas que presentaron los sobrevivientes ${ }^{45}$.

Respecto a la propiedad, tuvo por probado que los pobladores tuvieron que abandonar sus hogares y desplazarse como consecuencia de los saqueos en algunas de las viviendas y tiendas de Santo Domingo, así como daños y destrucciones a los bienes muebles e inmuebles ${ }^{46}$. A pesar de la gravedad del asunto, la sentencia no declara medidas de reparación referidas a las viviendas destruidas. La explicación es que, si bien lo solicitaron la Comisión IDH y los representantes de las víctimas, Colombia demostró acciones en vía administrativa en las que se había restituido -mediante indemnización - a la mayoría de las víctimas. La Corte dejó a salvo los derechos de cinco víctimas que no habían gozado de dichos beneficios otorgados, para que recibieran la indemnización material correspondiente ${ }^{47}$.

$\mathrm{Al}$ igual que en Santo Domingo, la sentencia del asunto Masacres de Ituango vs. Colombia ${ }^{48}$ sostuvo que la destrucción de los hogares, la privación del uso y goce de sus bienes como ganado y viviendas, además de la pérdida económica, causó pérdida de las condiciones básicas de la existencia y, con ello, declara la violación al derecho a la propiedad en conexión con el derecho a la circulación y residencia ${ }^{49}$.

${ }^{43}$ Corte IDH, Vereda La Esperanza vs. Colombia, párrs. 246-248.

${ }^{44}$ Corte IDH, Vereda La Esperanza vs. Colombia, párr. 305.

${ }^{45}$ Corte IDH, Masacre de Santo Domingo vs. Colombia, 30 noviembre 2012, párr. 267.

${ }^{46}$ Corte IDH, Masacre de Santo Domingo vs. Colombia, 30 noviembre 2012, párr. 274.

47 Corte IDH, Masacre de Santo Domingo vs. Colombia, 30 noviembre 2012, párrs. 336

y 337.

48 Corte IDH, 30 junio 2006.

49 Corte IDH, Masacres de Ituango vs. Colombia, 1 julio 2006, párr. 183. 
En este asunto, también ordena al Estado la reparación integral mediante indemnización de 6000 dólares americanos para cada una de las personas que perdieron sus viviendas ${ }^{50}$.

Para el caso de México, en los asuntos de desaparición forzada de personas, el Alto Tribunal interamericano hizo una conexión de temáticas de vivienda con la vulneración de los derechos a la vida, a la libertad personal, así como a la honra y dignidad. Por ejemplo, en el asunto Alvarado Espinoza y otros vs. México sostuvo que el Estado deberá brindar garantías de retorno o reubicación a las víctimas desplazadas que así lo requieran, mediante el otorgamiento de medidas de seguridad efectivas para un retorno digno a su lugar de residencia habitual, o bien su reasentamiento voluntario en otra parte del país ${ }^{51}$.

En particular, la sentencia acredita que los distintos grupos familiares de las personas desaparecidas en este asunto se vieron en la necesidad de realizar diversos desplazamientos en el territorio nacional y otros fuera de este y que las autoridades mexicanas tenían conocimiento de este contexto de amenazas, hostigamientos y muerte de un familiar y no dieron la protección efectiva que se requería para salvaguardar sus vidas e integridad personal; tampoco garantizó su derecho de circulación y residencia ${ }^{52}$ porque en virtud de tal contexto de violencia se vieron obligados a desplazarse, así como el derecho a la protección a la familia ${ }^{53}$ se vio vulnerado al no otorgarle la protección necesaria a pesar de contar con medidas provisionales de la propia Corte $^{54}$.

En este asunto, las medidas de reparación para los familiares de los desaparecidos ordenaron que México brindara garantías de retorno o reubicación a las víctimas desplazadas, ya sea mediante las medidas para un retorno digno a su lugar de residencia habitual, o bien otorgar un reasentamiento voluntario en otra parte del país 55 .

\subsubsection{Derechos a la vida y a la libertad personal}

En este grupo de sentencias se exponen aquellas en las que se declaró la violación al artículo 11 (protección de la honra y dignidad), pero también cita los derechos a la vida (artículo 4), el derecho a la libertad personal (artículo 7), todos de la $\mathrm{CADH}$. Los asuntos se refieren en contextos de violencia como desapariciones forzadas, masacres o privaciones ilegales y arbitrarias a la libertad personal, así como torturas o ejecuciones.

\footnotetext{
50 Corte IDH, Masacres de Ituango vs. Colombia, 1 julio 2006, párrs. 389-391.

51 Corte IDH, Alvarado Espinoza y otros vs. México, 28 noviembre 2018, párr. 277.

52 Artículo $22 \mathrm{CADH}$.

53 Artículo $17 \mathrm{CADH}$.

54 Corte IDH, Alvarado Espinoza y otros vs. México, 28 noviembre 2018, párr. 283.

55 Corte IDH, Alvarado Espinoza y otros vs. México, 28 noviembre 2012, párrs. 329-332.
} 
Es importante para lo que sigue advertir que el artículo 11 de la $\mathrm{CADH}$ protege el derecho a la honra y la dignidad en tres aspectos:

1. Toda persona tiene derecho al respeto de su honra y al reconocimiento de su dignidad.

2. Nadie puede ser objeto de injerencias arbitrarias o abusivas en su vida privada, en la de su familia, en su domicilio o en su correspondencia, ni de ataques ilegales a su honra o reputación.

3. Toda persona tiene derecho a la protección de la ley contra esas injerencias o esos ataques.

En el asunto Pueblo Bello, en 1990 un grupo de 60 personas armadas de un grupo guerrillero ingresaron a esta localidad saqueando viviendas, desalojando a los habitantes, llevándolos a la plaza del pueblo y a la iglesia, en donde eligieron a 43 hombres de una lista y los privaron de su libertad, fueron víctimas de tortura y, posteriormente, se les privó de la vida ${ }^{56}$.

En este asunto, debido a las pérdidas ocasionadas por las violaciones graves al artículo 11, la Corte IDH decretó que el Estado debe implementar un programa habitacional de vivienda adecuada para que los familiares regresen al lugar donde residían ${ }^{57}$.

Esta medida, la implementación de un "programa de vivienda» o "programa habitacional», está presente en las sentencias interamericanas como medida de reparación integral, ya sea como restitución ${ }^{58}$, o bien como satisfacción ${ }^{59}$; o incluso considerada como garantía de no repetición en asuntos que involucran a comunidades indígenas $s^{60}$.

En los asuntos que involucraron desaparición de personas ${ }^{61}$ destaco ahora el caso Comunidad Campesina Santa Bárbara vs. Perú ${ }^{62}$ porque la Corte refiere el artículo 21 relativo a la propiedad privada en este sentido: la quema de las viviendas de los miembros de esta comunidad es una violación del derecho al uso y disfrute de los bienes; sin embargo, razona diciendo que «constituye una injerencia abusiva y arbitraria en su vida privada y domicilio. Las personas que perdieron sus hogares perdieron el lugar donde desarrollaban dicha vida privada» ${ }^{63}$.

56 Corte IDH, Masacre Pueblo Bello vs. Colombia, 31 enero 2006, párr. 109.

57 Corte IDH, Masacre Pueblo Bello vs. Colombia, 31 enero 2006, párr. 276.

58 Corte IDH, Comunidad Campesina Santa Bárbara vs. Perú, 1 septiembre 2015, párrs. 300-304; Masacres de El Mozote y lugares aledaños vs. El Salvador, 25 octubre 2012, párr. 345-346.

59 Corte IDH, Masacres de Ituango vs. Colombia, 1 julio 2006, párr. 407 y Masacre Pueblo Bello vs. Colombia, 31 enero 2006, párr. 276.

${ }^{60}$ Corte IDH, Masacre Plan de Sánchez vs. Guatemala, 19 abril 2004, párr. 105.

${ }^{61}$ Corte IDH, Alvarado Espinosa y otros vs. México, 28 noviembre 2018; también en las sentencias de la comunidad de Vereda la Esperanza y las desapariciones de las masacres de Ituango y Pueblo Bello.

${ }^{62}$ Corte IDH, Comunidad Campesina Santa Bárbara vs. Perú, 1 septiembre 2015.

${ }^{63}$ Corte IDH, Comunidad Campesina Santa Bárbara vs. Perú, 1 septiembre 2015, párr. 205. 
El Tribunal condena a Perú a proveer de una vivienda adecuada a las víctimas a través de un programa habitacional que existe actualmente en el país en el plazo de un año; en caso de no cumplirse, deberá conmutar la pena por la indemnización que fija la sentencia ${ }^{64}$.

El otro asunto mexicano que también puso en evidencia el grave problema de la desaparición de personas en México es Trueba Arciniega y otros vs. México (Corte IDH, 27 noviembre 2018). Aquí no hubo proceso, sino que las partes llegaron a un acuerdo de solución amistosa que fue homologado por el Alto Tribunal a través de la sentencia que aquí se cita, en la cual se plasma la admisión total de responsabilidad del Estado mexicano y su compromiso con las víctimas -en relación con la vivienda- a través de dos medidas de satisfacción:

La primera consiste en la entrega de vivienda y de muebles a los dos familiares de la persona desaparecida (madre y hermano): a) entrega de los recursos para la compra de la vivienda en el domicilio donde vivían al momento de los hechos; y b) dicha vivienda tendrá las siguientes características: al menos cuatro habitaciones, un salón comedor, una cocina equipada, dos baños, lavandería y un patio grande. Y deberá entregarse la vivienda totalmente amueblada ${ }^{65}$.

La segunda medida que el Estado mexicano debe cumplir es la realización de las «mejoras de mantenimiento a la vivienda del señor José Tomás Trueba Loera», padre del joven Mirey Trueba, desaparecido a manos del Ejército mexicano en un contexto en el que el Estado mexicano otorgó las labores de orden público a elementos de la Fuerza Armada. En este caso, el acuerdo indica que México debe entregar una cantidad para que se realicen las mejores necesarias de su vivienda ubicada en Chihuahua de acuerdo con las visitas de inspección realizadas a dicha vivienda ${ }^{66}$. Ambas medidas deberán cumplirse en un plazo máximo de seis meses a partir de la fecha de la firma del acuerdo de solución amistosa.

\subsubsection{Derecho a la propiedad (colectiva)}

En este apartado se sistematizan las sentencias en las que la Corte IDH considera la protección a la vivienda desde la garantía al derecho a la propiedad en su modalidad «colectiva» o "comunitaria». Como se verá enseguida, los casos en los que este concepto ha sido creado ${ }^{67}-\mathrm{y}$ después desarrollado jurisprudencialmentepor la Corte fueron asuntos que involucran a comunidades y pueblos indígenas en un contexto de desplazamiento por la pérdida y/o desalojo de sus territorios.

${ }^{64}$ Corte IDH, Comunidad Campesina Santa Bárbara vs. Perú, 1 septiembre 2015, párr. 304.

${ }^{65}$ Corte IDH, Trueba Arciniega y otros vs. México, 27 noviembre 2018, párr. 47, C.2.

${ }^{66}$ Corte IDH, Trueba Arciniega y otros vs. México, 27 noviembre 2018, párr. 47, C.3.

${ }^{67} \mathrm{El}$ primer asunto en el que la Corte IDH inició la interpretación de la propiedad en su sentido "colectivo» fue en el asunto de la Comunidad Mayagna (Sumo) Awas Tingni vs. Nicaragua, 31 agosto 2001 . 
En efecto, en 2001 la Corte IDH, a través de una interpretación "evolutiva» de la normatividad internacional en materia de derechos humanos y la aplicación del artículo 29 de la CADH (en el sentido que prohíbe una interpretación restrictiva de los derechos), sostuvo que si bien el artículo 21 de la $\mathrm{CADH}$ protege la propiedad en un sentido amplio que comprende, además, "los derechos de los miembros de las comunidades indígenas en el marco de la propiedad comunal... ${ }^{68}$.

En el caso que se comenta la Corte estableció que el Estado generó condiciones que hicieron difícil el acceso a una vida digna de los miembros de la comunidad porque vieron afectada su forma de vida como consecuencia de la falta de sus tierras y la falta de acceso a los recursos naturales; además, en cuanto a su vivienda, vivieron en precariedad debido a que fueron desplazados de sus territorios ${ }^{69}$.

En este asunto, la falta de tierra, así como la carencia de los servicios mínimos como agua potable y atención médica, generaron que los miembros de esta comunidad sufrieran desempleo, analfabetismo, tasas de morbilidad, desnutrición y una marcada marginalización por causas naturales, geográficas y culturales ${ }^{70}$.

Por otro lado, el aspecto de la identidad cultural. En este ambito la Corte IDH también ha sido prolija al desarrollar una teoría sobre la cosmovisión que debe aplicarse cuando de pueblos indígenas se trata. Este entendimiento se basa en que el territorio ancestral donde habitan estas comunidades es el espacio en el cual se desarrolla y trasciende a las generaciones futuras la identidad cultural. En otras palabras, tener la propiedad de la tierra depende no sólo su subsistencia física, sino también su permanencia como unidad cultural. Es el territorio el asiento en el cual la identidad cultural, es decir, la lengua, las tradiciones, la religión, literatura, música, alimentación, costumbres y en general toda manifestación cultural, se conserva $y$, sobre todo, se transmite para las generaciones futuras de dicha comunidad.

La sentencia sostuvo que, aunque Paraguay reconoce en legislación el derecho a la propiedad comunitaria de las tierras y recursos naturales de los indígenas, el reconocimiento legal de este derecho carece de sentido si no se ha delimitado ni entregado las tierras a la comunidad por falta de medidas adecuadas, pues con ello se ha amenazado el libre desarrollo y transmisión de su cultura y prácticas tradicionales ${ }^{71}$.

A la fecha en que se redacta este documento ${ }^{72}$, la Corte IDH ha dictado 19 sentencias en las que aplicó este criterio jurisprudencia ${ }^{73}$. Ahora bien, interesa destacar aquí nueve sentencias en las que la Corte IDH hace una conexión directa del

${ }^{68}$ Corte IDH, Comunidad Mayagna (Sumo) Awas Tingni vs. Nicaragua, 31 agosto 2001, párr. 148.

${ }^{69}$ Corte IDH, Comunidad Indígena Yakye Axa vs. Paraguay, 17 junio 2001, párr. 164.

${ }^{70}$ Corte IDH, Comunidad Indígena Yakye Axa vs. Paraguay, 17 junio 2005, párr. 168.

${ }^{71}$ Corte IDH, Comunidad Indígena Yakye Axa vs. Paraguay, 17 junio 2005, párr. 148.

72 julio 2020.

73 Sobre este tema puede consultarse Cuadernillo de Jurisprudencia de la Corte Interamericana de Derechos Humanos, número 11: pueblos indígenas y tribales. Disponible en http://www. corteidh.or.cr/sitios/libros/todos/docs/cuadernillo11.pdf. 
concepto de propiedad colectiva con la protección a la vivienda de los miembros de estas comunidades indígenas por motivo de la pérdida de aquella ${ }^{74}$.

La conexión del derecho a la propiedad -en conexión con la vivienda- se hace a través de las consideraciones a los derechos a la circulación y residencia; a la vida y libertad personal como ejecuciones, privación de la vida e incluso torturas o tratos crueles y degradantes.

El grupo más numeroso (cinco casos) en el que la vivienda es protegida hace referencia conjuntamente al derecho de propiedad colectiva y las consecuencias de la vulneración del derecho a la circulación y residencia ${ }^{75}$ por diversos motivos como proyectos de desarrollo, por violencia generalizada en la zona, entre otros. Los cuatro asuntos restantes hacen referencia a la pérdida de la propiedad -y otros derechos- y el menoscabo de las condiciones necesarias para una vida digna de los miembros de las comunidades, así como para llevar a cabo prácticas y costumbres de su identidad cultural.

Respecto al segundo grupo de sentencias referido, en el asunto de la Comunidad Sawhoyamaxa vs. Paraguay ${ }^{76}$, a través de las medidas de reparación integral la Corte dispuso que

... la devolución de las tierras tradicionales a los miembros de la Comunidad Sawhoyamaxa es la medida de reparación que más se acerca a la restitutio in integrum, por lo que dispone que el Estado debe adoptar todas las medidas legislativas, administrativas y de cualquier otra índole necesarias para asegurar a los miembros de la Comunidad el derecho de propiedad sobre sus tierras tradicionales y, por lo tanto, su uso y goce.

Incluso, previó que como las tierras estaban en manos privadas, en virtud de que fueron concesionadas a una empresa particular para su explotación, el Estado deberá considerar la posibilidad de su compra o la necesidad de expropiación para lograr la devolución de las tierras ancestrales a la comunidad, o bien, si no es posible la devolución, entregarles tierras alternativas que sean suficientes para garanti-

${ }^{74}$ Para resumir este criterio interpretativo, la sentencia establece, respecto al derecho de propiedad de comunidades indígenas, lo siguiente: 1) la posesión tradicional de los indígenas sobre sus tierras tiene efectos equivalentes al título de pleno dominio que otorga el Estado; 2) la posesión tradicional otorga a los indígenas el derecho a exigir el reconocimiento oficial de propiedad y su registro; 3) los miembros de los pueblos indígenas que por causas ajenas a su voluntad han salido o perdido la posesión sus tierras tradicionales mantienen el derecho de propiedad sobre las mismas, aún a falta de título legal, salvo cuando las tierras hayan sido legítimamente trasladadas a terceros de buena fe; y 4) los miembros de los pueblos indígenas que involuntariamente han perdido la posesión de sus tierras, y éstas han sido trasladadas legítimamente a terceros inocentes, tienen el derecho de recuperarlas o a obtener otras tierras de igual extensión y calidad. Consecuentemente, la posesión no es un requisito que condicione la existencia del derecho a la recuperación de las tierras indígenas. El presente caso se encuadra dentro del último supuesto (Corte IDH, Comunidad Indígena Sawhoyamaka vs. Paraguay, 29 marzo 2006, párr. 128).

75 Artículos 21 y 22 de la CADH, respectivamente.

${ }^{76}$ Corte IDH, Comunidad Sawhoyamaxa vs. Paraguay, 29 marzo 2006, párr. 210. 
zar la forma de vida de la comunidad y, previo acuerdo de la misma ${ }^{77}$, en un plazo de tres años a partir de la notificación de la sentencia ${ }^{78}$.

En el mismo sentido, en el caso de la Comunidad Indigena Kakmok Kasek vs. Paraguay, el área reclamada por las víctimas desde 1990 es parte de su hábitat tradicional desde tiempos inmemoriales, por lo que tienen derecho a recuperar estas tierras o a obtener otras de igual extensión y calidad, de forma tal que se garantice su derecho a preservar y desarrollar su identidad cultural..$^{79}$ En las medidas de reparación, al igual que el asunto anterior, la sentencia señala que el Estado tendrá tres años para la devolución de las tierras tradicionales a los miembros de la Comunidad, ya sea por medio del procedimiento de expropiación, o bien deberá entregar tierras alternativas dentro del territorio tradicional de sus ancestros ${ }^{80}$.

En el asunto Pueblos indigenas Kuna Mandungani y Emberá de Bayano y sus miembros vs. Panamá $a^{81}$ también declaró la violación al artículo 21 en virtud de la pérdida del territorio ancestral de las comunidades. En tal sentido, la medida de reparación también fue en el sentido de establecer la obligación de Panamá de demarcar las tierras y la titulación a nombre de dichas comunidades.

En fechas más recientes, la Corte IDH dictó una sentencia histórica al declarar la vulneración de los derechos a la alimentación y al agua de la comunidad indígena Lhaka Honhat, en Argentina, a través de la aplicación directa del artículo 26 de la CADH. En lo que respecta al derecho a la propiedad colectiva, la sentencia reitera el criterio sostenido en los casos ya citados estableciendo el deber de este país de adoptar las medidas legislativas y/o de otro carácter que fueren necesarias para dotar de seguridad jurídica al derecho de propiedad comunitaria indígena ${ }^{82}$.

Respecto a comunidades indígenas que vivieron situaciones de desplazamientos, la Corte IDH dictó sentencia en el asunto Miembros de la Aldea de Chichupac y comunidades vecinas del municipio del Rabinal vs. Guatemala ${ }^{83}$, donde sostuvo que, si bien el Estado adoptó medidas como la construcción de viviendas en estas comunidades, no fueron suficientes y efectivas para garantizar a las personas desplazadas de esas comunidades la posibilidad de un retorno seguro a sus lugares de residencia habitual, o bien contar con un reasentamiento en otra parte del país, ni tampoco tuvieron una indemnización adecuada por la pérdida de sus viviendas. En este asunto, como en otros similares, dispuso como medidas de reparación el

77 Corte IDH, Comunidad Sawhoyamaxa vs. Paraguay, 29 marzo 2006, párrs. 211-212.

${ }^{78}$ Corte IDH, Comunidad Sawhoyamaxa vs. Paraguay, 29 marzo 2006, párr. 215.

${ }^{79}$ Corte IDH, Comunidad Indígena Kakmok Kasek vs. Paraguay, 24 agosto 2010, párr. 51.

${ }^{80}$ Corte IDH, Comunidad Indígena Kakmok Kasek vs. Paraguay, 24 agosto 2010, párrs. 285-286.

${ }^{81}$ Corte IDH, Pueblos indígenas Kuna Mandunganí y Emberá de Bayano y sus miembros vs. Panamá, 13 octubre 2014, párr. 232.

${ }^{82}$ Corte IDH, Miembros de la Asociación Lhaka Honhat (nuestra Tierra) vs. Argentina, 6 febrero 2020, párr. 354 .

${ }^{83}$ Corte IDH, Miembros de la Aldea de Chichupac y comunidades vecinas del municipio del Rabinal vs. Guatemala, 30 noviembre 2016, párr. 189. 
retorno colectivo a su lugar de origen de las víctimas desplazadas del pueblo indígena maya $a c h i^{84}$.

En el asunto contra Guatemala Masacre de Río Negro ${ }^{85}$, así como en el asunto de la Comunidad Afrodescendientes desplazadas de la Cuenca del Río Cacarica (Operación Génesis) vs. Colombia ${ }^{86}$, la Corte sostuvo la violación al artículo 22 de la CADH en virtud de los desplazamientos forzados de las comunidades indígenas debido a la destrucción de los hogares de los pobladores de estas comunidades, pues no sólo constituyeron pérdidas de tipo económico, también ocasionaron la pérdida de las condiciones básicas de existencia.

Por tanto, en las reparaciones, el Tribunal ordena al Estado que restituya el efectivo uso, goce y posesión de los territorios reconocidos en la normativa a las comunidades afrodescendientes agrupadas en el Consejo Comunitario del Cacarica $^{87}$, así como medidas de seguridad y vida digna de los territorios donde habitan actualmente ${ }^{88}$.

El caso de la Comunidad Moiwana vs. Suriname ${ }^{89}$, cuyos miembros fueron masacrados por las fuerzas armadas de Suriname, los que lograron escapar huyeron a bosques cercanos y algunos fueron posteriormente exiliados o desplazados en el interior del país; por tanto, la Corte declaró la vulneración de los dos derechos: la pérdida de la propiedad tradicional de la comunidad tribal y el desplazamiento forzado ${ }^{90}$.

Aquí la reparación fue en dos sentidos: por un lado, como medida de satisfacción, obligar al Estado a tomar las medidas legislativas, administrativas y de cualquier otra índole necesarias para asegurar a los miembros de la Comunidad Moiwana su derecho de propiedad sobre los territorios ancestrales de los que fueron expulsados y tener el uso y goce de dichos territorios ${ }^{11}$. Por el otro, como medida de restitución, la sentencia establece el deber del Estado de crear un Fondo de desarrollo financiado por el Estado que provea servicios sociales básicos a los miembros de la comunidad, cuando estos regresen ${ }^{92}$. Básicamente, el Fondo (de un millón doscientos mil dólares) estaría destinado a programas de salud, vivienda y educación para los miembros de la comunidad bajo la administración de un Comité de con-

${ }^{84}$ Corte IDH, Miembros de la Aldea de Chichupac y comunidades vecinas del municipio del Rabinal vs. Guatemala, 30 noviembre 2016, párr. 298.

${ }^{85}$ Corte IDH, Masacre de Río Negro vs. Guatemala, 4 octubre 2012.

${ }^{86}$ Corte IDH, Comunidad Afrodescendientes desplazadas de la Cuenca del Río Cacarica (Operación Génesis) vs. Colombia, 20 noviembre 2013, párr. 352.

${ }^{87}$ Corte IDH, Comunidad Afrodescendientes desplazadas de la Cuenca del Río Cacarica (Operación Génesis) vs. Colombia, párrs. 458-459.

${ }^{88}$ Corte IDH, Comunidad Afrodescendientes desplazadas de la Cuenca del Río Cacarica (Operación Génesis) vs. Colombia, párr. 460.

${ }^{89}$ Corte IDH, Comunidad Moiwana vs. Suriname, 15 junio 2005.

${ }^{90}$ Corte IDH, Comunidad Moiwana vs. Suriname, 15 junio 2005, párrs. 134-135.

${ }^{91}$ Corte IDH, Comunidad Moiwana vs. Suriname, 15 junio 2005, párrs. 208-211.

${ }_{92}$ Corte IDH, Comunidad Moiwana vs. Suriname, 15 junio 2005, párr. 213. 
formación mixta, es decir, de representantes de las víctimas y del Estado y un tercer miembro designado entre estos de común acuerdo ${ }^{93}$.

Otros asuntos importantes que involucraron desplazamiento de comunidades indígenas y también ejecuciones masivas son las masacres vividas en Guatemala: Masacre Plan de Sánchez ${ }^{94}$ y la Masacre de Río Negro ${ }^{95}$. Las medidas de reparación en estos asuntos tienen que ver con la reconstrucción de los lugares que habitaban antes de los episodios de violencia.

En el primer asunto, la sentencia estableció la obligación de Guatemala de un Programa de Vivienda mediante el cual se proveerá una vivienda adecuada en favor de cada uno de los sobrevivientes ${ }^{96}$. Para el segundo caso mencionado, la sentencia establece que Guatemala deberá realizar las obras de infraestructura y servicios básicos a favor de los miembros de la comunidad de Río Negro ${ }^{97}$.

Como se ha visto en estas sentencias, cuando la Corte IDH hizo la declaración de la vulneración de los derechos de propiedad -en conexión con otros como el derecho a la circulación y residencia, la libertad personal, la vida y vida privada, entre los principales-, dictó medidas de reparación a favor de las víctimas con el fin de que sean restituidos, ya sean sus territorios como en el caso de las comunidades indígenas, o bien los bienes inmuebles y muebles donde habitaban. Interesa, por tanto, verificar el grado de cumplimiento de estas sentencias en cuanto a la reparación integral de los daños ocasionados a las víctimas y sus familiares en materia habitacional.

\section{EL (IN) CUMPLIMIENTO DE LAS MEDIDAS DE REPARACIÓN INTEGRAL DE VIVIENDA EN LAS SENTENCIAS INTERAMERICANAS}

De las 21 sentencias dictadas por la Corte IDH en las que se encontró referencia a la protección a la vivienda de las víctimas se encontraron 28 medidas de reparación en materia habitacional. Sin embargo, solamente aparecen como "cumplidas totalmente» cuatro de ellas. Estas cuatro medidas cumplidas en materia de vivienda son:

1) Medida de indemnización, en la sentencia Masacre de Ituango vs. Colombia, cuyo plazo de cumplimiento fue de 55 meses y el Estado debía entregar una cantidad de 6000 dólares americanos a cada una de las víctimas para la compra de vivienda ${ }^{98}$.

93 Corte IDH, Comunidad Moiwana vs. Suriname, 15 junio 2005, párr. 212.

${ }^{4}$ Corte IDH, Masacre Plan de Sánchez vs. Guatemala, 29 abril 2004.

${ }^{5}$ Corte IDH, Masacre Río Negro vs. Guatemala, 4 octubre 2012.

${ }^{96}$ Corte IDH, Masacre Plan de Sánchez vs. Guatemala, 29 abril 2004, párr. 105.

${ }^{97}$ Corte IDH, Masacre Río Negro vs. Guatemala, 4 octubre 2012, párr. 248.

98 Corte IDH, Resolución de supervisión de cumplimiento, 28 febrero 2011. 
2) y 3) Las dos medidas dictadas en el asunto Comunidad Indígena Xákmok Kásek vs. Paraguay fueron cumplidas en cuanto a la remoción de los obstáculos para procesos de titulación ${ }^{99}$ y la segunda, la entrega de los títulos de propiedad a favor de la comunidad ${ }^{100}$.

4) La medida dictada en el asunto Defensor de Derechos Humanos y otros vs. Guatemala, referente al pago de la indemnización por los gastos ocasionados por el desplazamiento que sufrió la víctima y sus familiares ${ }^{101}$, cuya dilación demoró 26 meses.

Hay dos decisiones que tienen cumplimiento parcial ${ }^{102}$ : en el asunto Masacre de Ituango, sobre el programa de vivienda habitacional; y, la otra, en el asunto Yarce y otras vs. Colombia, respecto a la medida de indemnización para cubrir la pérdida de la propiedad privada de los familiares de las víctimas.

Por tanto, quedan 22 medidas de reparación en materia habitacional «pendientes de cumplimiento». Esta categoría alude a la falta total del acatamiento del Estado. La tabla 1 habla por sí sola de la situación respecto a las medidas de reparación a las que se ha hecho referencia.

\begin{tabular}{lcccc}
\hline \multicolumn{1}{c}{ PAís } & $\begin{array}{c}\text { NúmERo DE } \\
\text { MEDIDAS }\end{array}$ & Cumplidas & $\begin{array}{c}\text { PENDIENTES DE } \\
\text { CUMPLIMIENTO }\end{array}$ & $\begin{array}{c}\text { Cumplimiento } \\
\text { PARCIAL }\end{array}$ \\
\hline Argentina & 1 & 0 & 1 & 0 \\
\hline Colombia & 8 & 1 & 5 & 2 \\
\hline El Salvador & 1 & 0 & 1 & 0 \\
\hline Guatemala & 4 & 1 & 3 & 0 \\
\hline México & 2 & 0 & 2 & 0 \\
\hline Paraguay & 6 & 2 & 4 & 0 \\
\hline Panamá & 2 & 0 & 2 & 0 \\
\hline Perú & 1 & 0 & 1 & 0 \\
\hline Suriname & 1 & 0 & 1 & 0 \\
\hline Venezuela & 2 & 0 & 2 & 0 \\
\hline Total & 28 & 4 & 22 & 2 \\
\hline
\end{tabular}

Fuente: elaboración propia, con información obtenida de la página oficial de la Corte IDH.

99 Corte IDH, Resolución de supervisión de cumplimiento, 24 junio 2012.

100 Corte IDH, Resolución de supervisión de cumplimiento, 30 agosto 2017.

101 Corte IDH, Resolución de supervisión de cumplimiento, 22 noviembre 2016.

102 Este criterio lo otorga el Tribunal cuando el Estado ha demostrado dar trámite o cumplimiento a la medida ordenada por él; sin embargo, a juicio de la propia Corte o por desacuerdo de los víctimas no se puede considerar cumplida totalmente la medida. 


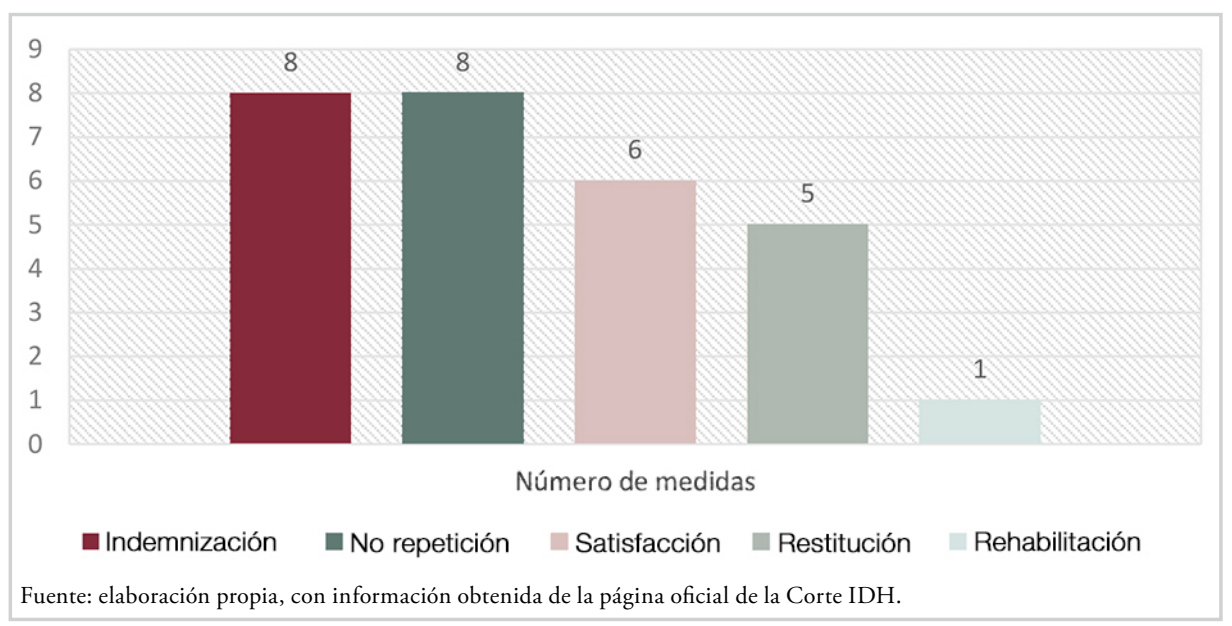

Gráfica 1. Medidas de reparación en materia de vivienda.

Otro dato que podría ser útil en cuanto a la forma en que la Corte IDH identifica las medidas de reparación que involucran la vivienda y los bienes perdidos por las víctimas es la categoría en la cual es incluida la medida. Como es sabido, en materia de reparación integra ${ }^{103}$, la doctrina jurisprudencial interamericana ha hecho un catálogo de los tipos de medidas: indemnización, rehabilitación, garantías de no repetición, satisfacción y restitución. Y también es conocido que la medida que más cumplen es la indemnización, debido a que puede ser acelerado su cumplimiento al otorgar un suma determinada de dinero a las víctimas, cuando el caso así lo permita. Al respecto la gráfica 1 . Número de medidas por rubro.

Cada uno de ellos refiere a un aspecto particular de la medida; por ejemplo, en la primera categoría se engloban los gastos materiales e inmateriales por motivo de la sustanciación del proceso judicial llevado a cabo por la víctima y sus familiares y, además, regularmente la Corte IDH incluye aquí las pérdidas en materia de bienes muebles e inmuebles. No por ello, de las 28 medidas de reparación en materia de vivienda se ubican en este rubro ocho de dichas medidas.

En cuanto a la rehabilitación (una medida), consiste en una forma de reparar a las víctimas como el otorgar el título de propiedad a la Comunidad Kakmok Kásek de las tierras que habían perdido. Respecto a las garantías de no repetición, la Corte IDH ha tenido un criterio variable. En el caso de estas sentencias, encontra-

103 Calderón Gamboa, J.F., «La reparación integral en la jurisprudencia de la Corte Interamericana de Derechos Humanos: estándares aplicables al nuevo paradigma mexicano", Derechos Humanos en la Constitución: Comentarios de Jurisprudencia Constitucional e interamericana, Instituto de Investigaciones Jurídicas-UNAM, 2013, pp. 145-219. 
mos ocho medidas de no repetición. Los ejemplos son variados: adopción de medidas legislativas y administrativas para que las comunidades indígenas no vuelvan a perder sus propiedades comunales ${ }^{104}$, otorgamiento de títulos de propiedad colectiva ${ }^{105}$, garantías de retorno o de reubicación a las víctimas por desplazamiento forzoso y pérdida de vivienda ${ }^{106}$, o bien programas habitacionales para las comunidades que vieron destruidas sus viviendas y hogares por motivo de la violencia ${ }^{107}$.

Las medidas de restitución (cinco medidas) hacen referencia a la entrega a las víctimas de lo perdido, por ejemplo, entrega de alpacas, ganado y viviendas ${ }^{108}$, viviendas para el retorno seguro ${ }^{109}$. Finalmente, en el rubro de "satisfacción», las seis medidas que aparecen en este grupo de sentencias hacen referencia a deberes del Estado en relación con suministro de bienes y servicios básicos para la vivienda para los habitantes de la Comunidad indígena Sawhoyamaxa y la Comunidad de Río Negro; y, un programa habitacional para los sobrevivientes y familiares de las víctimas de la Masacre Pueblo Bello y Masacre de Ituango. La tabla 2 presenta la anterior información en forma sistematizada.

\begin{tabular}{|c|c|c|c|c|}
\hline \multicolumn{5}{|c|}{ TABLA 2. NÚMERO DE MEDIDAS POR RUBRO } \\
\hline Rubro & $\begin{array}{l}\text { NÚMERO DE } \\
\text { MEDIDAS }\end{array}$ & Cumplidas & $\begin{array}{l}\text { Pendientes de } \\
\text { CUMPlimiento }\end{array}$ & $\begin{array}{c}\text { Cumplimiento } \\
\text { PARCIAL }\end{array}$ \\
\hline Indemnización & 8 & 2 & 5 & 1 \\
\hline Rehabilitación & 1 & 1 & 0 & 0 \\
\hline No repetición & 8 & 1 & 7 & 0 \\
\hline Restitución & 5 & 0 & 5 & 0 \\
\hline Satisfacción & 6 & 0 & 5 & 1 \\
\hline Total & 28 & 4 & 22 & 2 \\
\hline
\end{tabular}

Fuente: elaboración propia, con información obtenida de la página oficial de la Corte IDH.

104 Corte IDH, Miembros de la Asociación Lhaka Honhat (Nuestra Tierra) vs. Argentina, 6 febrero 2020.

105 Corte IDH, Pueblos Indígenas Kuna de Mandunganí y Emberá de Bayano y sus miembros vs. Panamá, 13 octubre 2014

106 Corte IDH, Alvarado Espinosa vs. México, 28 noviembre 2018.

107 Corte IDH, Masacre Plan de Sánchez vs. Guatemala, 29 abril 2004.

108 Corte IDH, Comunidad Campesina Santa Bárbara vs. Perú, 1 octubre 2015.

109 Corte IDH, en los casos de Masacres de El Mozote y lugares aledaños, Comunidad de Afrodescendientes desplazadas de la Cuenca del Río Cacarica (Operación Génesis), Miembros de la Aldea de Chichupac y comunidades vecinas del municipio del Rabinal. 


\section{REFLEXIONES FINALES: VOCES PARA LA CONSIDERACIÓN DE UN DERECHO AUTÓNOMO DE LA VIVIENDA EN EL SISTEMA INTERAMERICANO}

Hasta aquí he presentado una sistematización del panorama jurisprudencial de los casos en los que la Corte IDH ha realizado una protección a la vivienda mediante la técnica de conexión con otros derechos, particularmente con el derecho a la propiedad y con el derecho a la circulación y residencia, ambos reconocidos por los artículos 21 y 22 de la Convención.

Para realizar las últimas consideraciones a esta temática estimo relevante señalar algunos planteamientos judiciales en el sistema interamericano que llaman a revisar la justiciabilidad directa del derecho a la vivienda mediante la interpretación al artículo 26 de la Convención, como ya lo ha hecho el Tribunal de San José en asuntos relacionados con el derecho a la salud, al empleo o la seguridad social.

Los argumentos en esta temática van en el mismo sentido y dirección que los anteriores asuntos de DESCA reconocidos en sede interamericana a partir de la interpretación del artículo 26 de la Convención. Por tanto, más allá de reiterar dichos planteamientos aquí me parece que existen otros singulares motivos para considerar el eventual reconocimiento autónomo del derecho a la vivienda en una impronta no muy lejana y, sobre todo, por las consecuencias para la protección a este derecho en la región, como un auténtico derecho humano.

Uno de estos motivos y, en mi opinión, el más relevante -por lo controvertido que resulta- es aquel que descansa en la falta de protección y reconocimiento expreso del derecho a la vivienda tanto en la Convención como en el Protocolo San Salvador. El argumento sostiene que, al asumir jurisdiccionalmente la protección del derecho a la vivienda, se sigue la interpretación judicial adoptada en los casos relativos a la salud, alimentación e incluso del agua, es decir, a través de la interpretación evolutiva y la aplicación del iuris corpus interamericano, tal como lo ha sostenido en estos casos el Alto Tribunal interamericano.

En el caso Yarce y otras vs. Colombia, el voto concurrente del juez Ferrer Mac-Gregor sostuvo que el asunto destaca por dos hechos: la labor de defensoras de derechos humanos, es decir, la protección a las mujeres y su labor; y, por otro lado, la pérdida de la vivienda en los contextos de desplazamiento forzado interno que se expone en el caso mencionado.

Este mismo sentido judicial fue reiterado en la sentencia Vereda La Esperanza vs. Colombia ${ }^{110}$. En este asunto, relativo a una comunidad cuyos miembros fueron privados de la vida, desaparecidos niños, niñas y adultos y ejecuciones arbitrarias, en el que los sobrevivientes fueron forzados a dejar sus viviendas, campos, cultivos y ganados. En este caso se consideró de especial gravedad la pérdida de las condiciones de existencia digna de las víctimas y su situación de vulnerabilidad.

110 Voto concurrente del juez Eduardo Ferrer Mac-Gregor Poisot en el caso Vereda La Esperanza vs. Colombia, 31 agosto 2017, párrs. 7 y ss. 
Otro argumento que se emplea para sostener la viabilidad de la tesis a favor de la justiciabilidad hace referencia al desarrollo que la Corte IDH ha realizado del concepto de propiedad (tanto privada como comunal), como protección de los bienes que forman parte del patrimonio de las personas, tanto muebles como inmuebles.

Sin embargo, para separarse de este criterio el voto del juez Mac-Gregor expone que el concepto de «vivienda" puede quedar protegido dentro del derecho de propiedad, pero no necesariamente toda propiedad es necesariamente vivienda ${ }^{111}$. Este discernimiento sigue a lo establecido por la Comité DESC ONU al expresar que el derecho a la vivienda «es el derecho de toda persona a un hogar seguro, asequible y habitable» ${ }^{112}$, lo cual no siempre comprende a la propiedad. En tal sentido, pueden ubicarse en esta línea argumentativa los casos en que las destrucciones o afectaciones a la vivienda y los bienes que la integran que sean atribuibles al Estado deben ser protegidos por un derecho autónomo que así lo comprenda.

Otro argumento que se ha sostenido tiene que ver con la «interdependencia» de los derechos humanos. La sentencia sobre el caso Lhaka Honhat es muestra de esto. Sostuvo el Tribunal que en el caso de los pueblos indígenas la pérdida de territorios o tierras no necesariamente presenta relación con el derecho de propiedad; incluso plantea que pueden existir lesiones a otros derechos que, vinculados con el territorio, pueden ser analizados desde un enfoque distinto al de la propiedad, como lo hizo en la sentencia antes mencionada al declarar la violación de los derechos a la alimentación y al agua de la comunidad ${ }^{113}$ partiendo de un examen desde la óptica del artículo 26 ya citado.

Una reflexión final tendría también como propósito llamar la atención sobre dos aspectos para la protección del derecho a la vivienda. El primer aspecto tiene que ver con las medidas de reparación impuestas por la Corte IDH para reparar los daños ocasionados tanto a las víctimas como a sus familiares. Aquí se ha visto que las sentencias imponen a los Estados obligaciones en torno a la devolución de sus tierras, al establecimiento de programas habitacionales, a la compensación económica por la pérdida de las viviendas y sus muebles, entre otras medidas.

Sin embargo, y esto nos lleva al segundo aspecto, el cumplimiento de estas medidas queda muy debajo del porcentaje de cumplimiento de las sentencias de la Corte IDH ${ }^{114}$.

Las sentencias que han visto cumplidas las medidas de reparación en materia habitacional se desahogan mejor -más rápido- vía la indemnización. La experiencia en las medidas de no repetición o satisfacción en la Corte IDH dice que los

${ }_{111}$ Voto concurrente del juez Eduardo Ferrer Mac-Gregor Poisot en el caso Vereda La Esperanza vs. Colombia, 31 agosto 2017, párr. 24.

112 Voto concurrente del juez Eduardo Ferrer Mac-Gregor Poisot en el caso Vereda La Esperanza vs. Colombia, 31 agosto 2017, párr. 25.

113 Voto concurrente del juez Eduardo Ferrer Mac-Gregor Poisot en el caso Vereda La Esperanza vs. Colombia, 31 agosto 2017, párr. 40.

114 Academia Interamericana de Derechos Humanos, Informe de Ejecución de Sentencias de la Corte IDH 1988-2018, México, 2019. 
Estados demoran más en tomar las medidas tanto legislativas cuanto administrativas para llevar a cabo sus deberes. Las medidas de política pública, de presupuesto, de involucramiento con las demás ramas del Estado dicen que la demora será mayor. Tratándose de un bien básico para la vida digna, como es el tener un «techo» donde vivir, no parecen ser el remedio más efectivo para las víctimas.

Recibido: septiembre de 2020; ACEPTADo: diciembre de 2020 
